\title{
Vaccination with recombinant adenovirus expressing multi-stage antigens of Toxoplasma gondii by the mucosal route induces higher systemic cellular and local mucosal immune responses than with other vaccination routes
}

\author{
Ting Wang ${ }^{1, a}$, Huiquan Yin ${ }^{1, a}$, Yan $\mathrm{Li}^{1, \mathrm{a}}$, Lingxiao $\mathrm{Zhao}^{2}$, Xiahui $\mathrm{Sun}^{1}$, and Hua Cong ${ }^{1, *}$ \\ 1 Department of Human Parasitology, Shandong University, School of Medicine, No. 44 Wenhuaxi Road, Jinan, \\ Shandong 250012, P.R. China \\ 2 Shandong Xiehe University, No. 6277 Jiqing Road, Jinan, Shandong 250107, P.R. China
}

Received 11 October 2016, Accepted 17 March 2017, Published online 3 April 2017

\begin{abstract}
Toxoplasmosis caused by Toxoplasma gondii, an obligate intracellular protozoan, is a cause of congenital disease and abortion in humans and animals. Various vaccination strategies against toxoplasmosis in rodent models have been used in the past few decades; however, effective vaccines remain a challenge. A recombinant adenovirus vaccine expressing ubiquitin-conjugated multi-stage antigen segments (Ad-UMAS) derived from different life-cycle stages of $T$. gondii was constructed previously. Here, we compared the immune responses and protection effects in vaccination of mice with Ad-UMAS by five vaccination routes including intramuscular (i.m.), intravenous (i.v.), subcutaneous (s.c.), intraoral (i.o.), and intranasal (i.n.). Much higher levels of $T$. gondii-specific IgG and $\operatorname{IgA}$ antibodies were detected in the sera of the intraoral and intranasal vaccination groups on day 49 compared with controls $(p<0.05)$. The percentages of $\mathrm{CD} 8^{+} \mathrm{T}$-cells in mice immunized intranasally and intraorally were larger than in mice immunized intramuscularly $(p<0.05)$. The highest level of IL-2 and IFN- $\gamma$ was detected in the group with nasal immunization, and splenocyte proliferation activity was significantly enhanced in mice immunized via the oral and nasal routes. Furthermore, the higher survival rate $(50 \%)$ and lower cyst numbers observed in the intraoral and intranasal groups all indicate that Ad-UMAS is far more effective in protecting mice against $T$. gondii infection via the mucosal route. Ad-UMAS could be an effective and safe mucosal candidate vaccine to protect animals and humans against T. gondii infection.
\end{abstract}

Key words: Toxoplasma gondii, Vaccine, Recombinant adenovirus, Mucosal vaccination.

\begin{abstract}
Résumé - La vaccination par adénovirus recombinant exprimant des antigènes multi-stades de Toxoplasma gondii par voie muqueuse induit des réponses immunitaires systémiques cellulaires et locales muqueuses meilleures que d'autres voies de vaccination. La toxoplasmose, causée par Toxoplasma gondii, un protozoaire intracellulaire obligatoire, est une cause de maladie congénitale et d'avortement chez l'homme et chez l'animal. Différentes stratégies de vaccination contre la toxoplasmose, chez les rongeurs, ont été employées au cours des dernières décennies, mais obtenir un vaccin efficace demeure un défi. Un vaccin d'adénovirus recombinant exprimant des segments d'antigènes multi-stades conjugués à l'ubiquitine (Ad-UMAS), dérivés de différents stades du cycle de vie de T. gondii, a été construit précédemment. Dans cette étude, nous avons comparé les réponses immunitaires et les effets de protection de la vaccination des souris avec Ad-UMAS par cinq voies de vaccination, y compris intramusculaire, intraveineuse, sous-cutanée, intra-orale et intranasale. Des taux beaucoup plus élevés d'anticorps IgG et IgA spécifiques de $T$. gondii ont été détectés dans le sérum des groupes de souris des vaccinations intra-orales et intranasale au jour 49 , par rapport aux témoins $(p<0.05)$. Les pourcentages de lymphocytes $\mathrm{CD}^{+}$sont plus importants chez les souris immunisées par voie intranasale et intraorale que chez les souris immunisées par voie intramusculaire $(p<0.05)$. Le niveau le plus élevé d'IL-2 et d'IFN-y a été détecté dans le groupe d'immunisation nasale et l'activité de prolifération des splénocytes a été significativement augmentée chez les souris immunisées par voie orale et nasale. En outre, un taux de survie plus élevé (50\%) et
\end{abstract}

\footnotetext{
${ }^{a}$ These authors contributed equally to this work.

*Corresponding author: conghua@sdu.edu.cn
}

This is an Open Access article distributed under the terms of the Creative Commons Attribution License (http://creativecommons.org/licenses/by/4.0), which permits unrestricted use, distribution, and reproduction in any medium, provided the original work is properly cited. 
plus petit nombre de kystes observés dans les groupes intra-oraux et intranasaux indiquent qu'Ad-UMAS est beaucoup plus efficace pour protéger les souris contre l'infection par $T$. gondii par voie muqueuse. Ad-UMAS pourrait être un candidat vaccin par voie muqueuse efficace et sûr pour protéger les animaux et les humains contre l'infection par T. gondii.

\section{Introduction}

Toxoplasma gondii is a single-cell obligate intracellular protozoan with an infection rate of approximately $25 \%-30 \%$ in the worldwide population $[6,13,29]$. In pregnant women, this parasite may threaten health or even be fatal concerning congenitally infected fetuses [30]. It is also a major opportunistic infection in immunodeficient individuals, causing toxoplasmic encephalitis and retinochoroiditis [7, 17, 33]. As a result, an effective vaccine against $T$. gondii is urgently needed to prevent this disease.

Various vaccination strategies against toxoplasmosis in rodent models have been used in the last few decades. However, effective vaccines remain a challenge as tested vaccines have not been able to confer sterile immunity against infection [19]. Current research on $T$. gondii vaccines only focuses on antigens expressed in the tachyzoite stage, which only induce partial protective immunity [20, 28, 38, 44]. The development of a variety of epitope combinations from different stages of the life cycle, including tachyzoites, bradyzoites (in tissue cysts), and sporozoites (in oocysts), are likely to induce full protection [2, 3, 4, 43]. With the development of bioinformatics, epitope vaccines are considered a novel immunization approach to prevent $T$. gondii infection. In addition, an appropriate delivery system of vaccines could increase the transfection efficiency of immune cells.

Adenovirus, which can penetrate host cells delivering vaccine antigen to antigen-presenting cells (APCs) and elicit vigorous and sustained T-cell responses, is a promising T. gondii vaccine vector and can be used effectively to transport immunogens [27]. Recent studies have also found that recombinant canine adenovirus type- 2 expressing TgROP16 and TgROP18 provides partial protection against acute $T$. gondii infection in mice, and indicate that adenovirus vectors may be potentially useful in the development of an effective vaccine against $T$. gondii infection [21,22].

The mucosal immune system consisting of specialized epithelial cells can trigger both humoral and cell immune responses when antigens are administered with appropriate adjuvants or attenuated live vaccines via mucosal routes (oral, nasal, sublingual, ocular, genital, or rectal) $[18,23]$. Furthermore, local mucosal immunization can lead to antigen-specific $\mathrm{T}$ - and B-cell responses not only in mucosal sites but also systemically [5, 24]. Hence, there is a greater need for effective vaccines that exert protective effects at mucosal surfaces, especially for intracellular parasites such as $T$. gondii.

In this research, we utilize a recombinant adenovirus vaccine expressing ubiquitin-conjugated multi-stage antigen segments (Ad-UMAS) derived from different life-cycle stages of T. gondii to evaluate the immune responses obtained with the different intramuscular vaccination routes described in our earlier study [41]. To further explore the optimal immune pathway for this recombinant adenovirus $T$. gondii vaccine, we plan to determine the immune responses and protection efficacy by vaccinating BALB/c mice via five routes (intramuscular (i.m.), intravenous (i.v.), subcutaneous (s.c.), intraoral (i.o.), and intranasal (i.n.)).

\section{Materials and methods}

\section{Ethics approval}

All the experimental procedures with animals used in the present study were granted prior approval by the Institutional Animal Care and Use Committee of Shandong University under Contract LL201602044. Humane endpoints are chosen to terminate the pain or distress of the experimental animals via euthanasia. Mice were monitored daily over 11 weeks for signs of toxoplasmosis including food and water intake difficulties, fatigue, severe ascites, and any test animals that showed signs of illness were euthanized immediately with $\mathrm{CO}_{2}$ gas.

\section{Parasites}

Tissue cysts of the low-virulence Prugniaud (PRU) strain (type II) and tachyzoites of the high-virulence RH strain (type I) of T. gondii, which were a kindly provided by Professor Xingquan Zhu at Lanzhou Veterinary Research Institute, were propagated and harvested as described in our previous studies [41], and then used for the in vivo challenge of mice.

\section{Construction of the recombinant adenovirus vaccine}

Ad-UMAS vaccine was constructed as previously described [40]. Briefly, Ad-UMAS was constructed using the AdMAX system (Hanbio, Shanghai, China). The ubiquitinconjugated multi-stage antigen segments (UMAS) were cloned into a shuttle plasmid, pHBAd-MCMV-GFP. Ad-UMAS was generated by homologous recombination of pHBAd-MCMVGFP-UMAS with pHBAd-BHG in HEK-293 cells. Ad-UMAS particles, with a titer of $10^{11}$ plaque-forming units (PFU)/mL, were purified by cesium chloride gradient centrifugation and then stored in storage buffer $\left(10 \mathrm{mM}\right.$ Tris, $2 \mathrm{mM} \mathrm{MgCl}_{2}$, and $5 \%$ sucrose, $\mathrm{pH} 8.0$ ) at $-80{ }^{\circ} \mathrm{C}$.

\section{Mice immunization}

Specific-pathogen-free female BALB/c mice aged 6-8 weeks were purchased from Shandong University Laboratory Animal Centre (Jinan, China). The animals for vaccination included intramuscular, intravenous, subcutaneous, intraoral, 
and intranasal immunization groups (15 mice per group). For the intramuscular group, the mice were injected $100 \mu \mathrm{L}$ $\left(3 \times 10^{8}\right.$ PFU) Ad-UMAS in the quadriceps muscle. For the intravenous group, the mice were injected $50 \mu \mathrm{L}$ $\left(3 \times 10^{8}\right.$ PFU) Ad-UMAS in the caudal vein. The subcutaneous and oral groups were administered $200 \mu \mathrm{L}$ $\left(3 \times 10^{8}\right.$ PFU) Ad-UMAS by subcutaneous injection and intragastric administration. For intranasal vaccinations, mice were anesthetized with $3 \%$ isoflurane in oxygen and were given a nasal drip of $10 \mu \mathrm{L}\left(3 \times 10^{8} \mathrm{PFU}\right)$ Ad-UMAS with the head canted $45^{\circ}$ for $10 \mathrm{~min}$. Each group also had 15 mice that were treated with phosphate-buffered saline (PBS) as the control. Mice were vaccinated twice at 3 -week intervals. Table 1 summarizes the treatments given to the mice. Figure 1 shows the study flowchart for vaccinated mice.

\section{Measurement of humoral response}

Serum samples were collected by retro-orbital bleeding on days $0,14,35$, and 49 . Standard ELISAs were used to determine the levels of $T$. gondii-specific antibodies, IgG, IgG1, $\operatorname{IgG} 2 \mathrm{a}$, and $\operatorname{IgA}$, in the serum samples from the inoculated mice. This was done with some changes to the method previously described [3, 5]. Briefly, a flat-bottom 96-well plate was pre-coated with the UMAS peptide pool at a concentration of $10 \mu \mathrm{g} / \mathrm{mL}$ in a $50 \mathrm{mM}$ carbonate-bicarbonate buffer ( $\mathrm{pH} 9.6)$ overnight at $4{ }^{\circ} \mathrm{C}$. The mouse sera were diluted in PBS $(1: 100)$ and incubated at $37^{\circ} \mathrm{C}$ for $1 \mathrm{~h}$. After washing the plates, bound antibodies were then reacted with horseradish peroxidase (HRP)-conjugated goat anti-mouse IgG, IgG1, IgG2a, or IgA (Sigma-Aldrich, USA) at $37^{\circ} \mathrm{C}$ for $1 \mathrm{~h}$. Peroxidase activity was revealed by $3,3^{\prime}, 5,5^{\prime}$-tetramethylbenzidine (TMB, $10 \mathrm{mg} / \mathrm{mL}$ ) and stopped by adding $50 \mu \mathrm{L}$ of $2 \mathrm{M}$ $\mathrm{H}_{2} \mathrm{SO}_{4}$. The optical density (OD) at $450 \mathrm{~nm}$ was measured by a Thermo Scientific Multiskan FC Microplate Photometer (Thermo Scientific, USA).

\section{Lymphocyte proliferation assay}

Spleens were removed from three immunized mice per group four weeks after the last immunization. Single-cell splenocytes were harvested following the method described in a previous study $[5,42]$. Isolated splenocytes were plated in 96-well plates, at a density of $1 \times 10^{6}$ per well, in $100 \mu \mathrm{L}$ RPMI-1640 medium (Sigma-Aldrich, USA) supplemented with $10 \%$ fetal calf serum and cultured with Concanavalin A (ConA, $2 \mu \mathrm{g} / \mathrm{mL}$, Sigma-Aldrich) or the UMAS peptide pool $(10 \mu \mathrm{g} / \mathrm{mL})$. Cell proliferative activity was measured according to the manufacturer's instructions on a Dojindo Cell Counting Kit-8 (Dojindo, Japan). The results were expressed as absorbance at $450 \mathrm{~nm}$.

\section{Cytokine production}

The level of cytokine production was determined using splenocytes from three mice per group 4 weeks after the last immunization. Commercial ELISA Kits (R\&D Systems,
Table 1. Summary of treatments in BALB/c mice.

\begin{tabular}{|c|c|c|}
\hline $\begin{array}{l}\text { Vaccination } \\
\text { pathway }^{\mathrm{a}}\end{array}$ & Treatments $^{\mathrm{b}}$ & $\begin{array}{c}\text { Mice } \\
\text { number }^{\mathrm{c}}\end{array}$ \\
\hline \multirow[t]{2}{*}{ Intramuscular } & $100 \mu \mathrm{L}$ PBS & 15 \\
\hline & $\begin{array}{l}100 \mu \mathrm{L}\left(3 \times 10^{8} \text { PFU }\right) \text { Ad- } \\
\text { UMAS }\end{array}$ & 15 \\
\hline \multirow[t]{2}{*}{ Intravenous } & $50 \mu \mathrm{L}$ PBS & 15 \\
\hline & $50 \mu \mathrm{L}\left(3 \times 10^{8}\right.$ PFU $)$ Ad-UMAS & 15 \\
\hline \multirow[t]{2}{*}{ Subcutaneous } & $200 \mu \mathrm{L}$ PBS & 15 \\
\hline & $\begin{array}{l}200 \mu \mathrm{L}\left(3 \times 10^{8} \mathrm{PFU}\right) \\
\text { Ad-UMAS }\end{array}$ & 15 \\
\hline \multirow[t]{2}{*}{ Intraoral } & $200 \mu \mathrm{L}$ PBS & 15 \\
\hline & $\begin{array}{l}200 \mu \mathrm{L}\left(3 \times 10^{8} \mathrm{PFU}\right) \\
\text { Ad-UMAS }\end{array}$ & 15 \\
\hline \multirow[t]{2}{*}{ Intranasal } & $20 \mu \mathrm{L}$ PBS & 15 \\
\hline & $20 \mu \mathrm{L}\left(3 \times 10^{8}\right.$ PFU $)$ Ad-UMAS & 15 \\
\hline
\end{tabular}

${ }^{a}$ The mice were randomly divided into intramuscular, intravenous, subcutaneous, intraoral, and intranasal immunization groups (15 mice per group).

${ }^{b}$ For the intramuscular group, the mice were injected $100 \mu \mathrm{L}$ $\left(3 \times 10^{8} \mathrm{PFU}\right)$ Ad-UMAS vaccine in the quadriceps muscle. For the intravenous group, the mice were injected $50 \mu \mathrm{L}\left(3 \times 10^{8}\right.$ PFU $)$ Ad-UMAS vaccine in the caudal vein. The subcutaneous and oral groups were each administered $200 \mu \mathrm{L}\left(3 \times 10^{8} \mathrm{PFU}\right)$ Ad-UMAS vaccine. For the nasal group, each mouse was given a nasal drip of $20 \mu \mathrm{L}\left(3 \times 10^{8}\right.$ PFU) Ad-UMAS vaccine.

${ }^{c}$ Each group also had 15 mice which were treated with PBS as negative control. Mice were vaccinated twice at 3-week intervals.

USA) were used following the manufacturer's instructions to assay IL-2 at $24 \mathrm{~h}, \mathrm{IL}-10$ at $72 \mathrm{~h}$, and IFN- $\gamma$ at $96 \mathrm{~h}$ in culture supernatants obtained as previously described [40]. This was done by collecting the cell supernatant of three wells from the 96-well plates and centrifuging to discard cell debris. The supernatant was tested for cytokines. The detection was replicated three times for each spleen.

\section{Cell surface staining of murine splenic lymphocytes}

Cells were stained with fluorescein isothiocyanate (FITC)labeled anti-mouse $\mathrm{CD}^{+}$monoclonal antibody and phycoerythrin (PE)-labeled anti-mouse $\mathrm{CD}^{+}$monoclonal antibody; Tlymphocyte subsets were measured by a Beckman Coulter FC500 Flow Cytometer (Beckman Coulter, USA).

\section{Challenge study of immunized mice}

Four weeks after the last immunization, mice were challenged with the type 1 or type 2 parasites to evaluate the protective effect. Six mice per group were infected intraperitoneally with $1 \times 10^{3}$ tachyzoites of $T$. gondii $\mathrm{RH}$ strain (type 1 parasite) after the last immunization, and the survival time of the mice was observed and recorded.

Another six immunized mice per group were infected via the gastric route with 20 cysts of the T. gondii PRU (type 2 parasite) strain. The challenged mice were sacrificed 4 weeks 


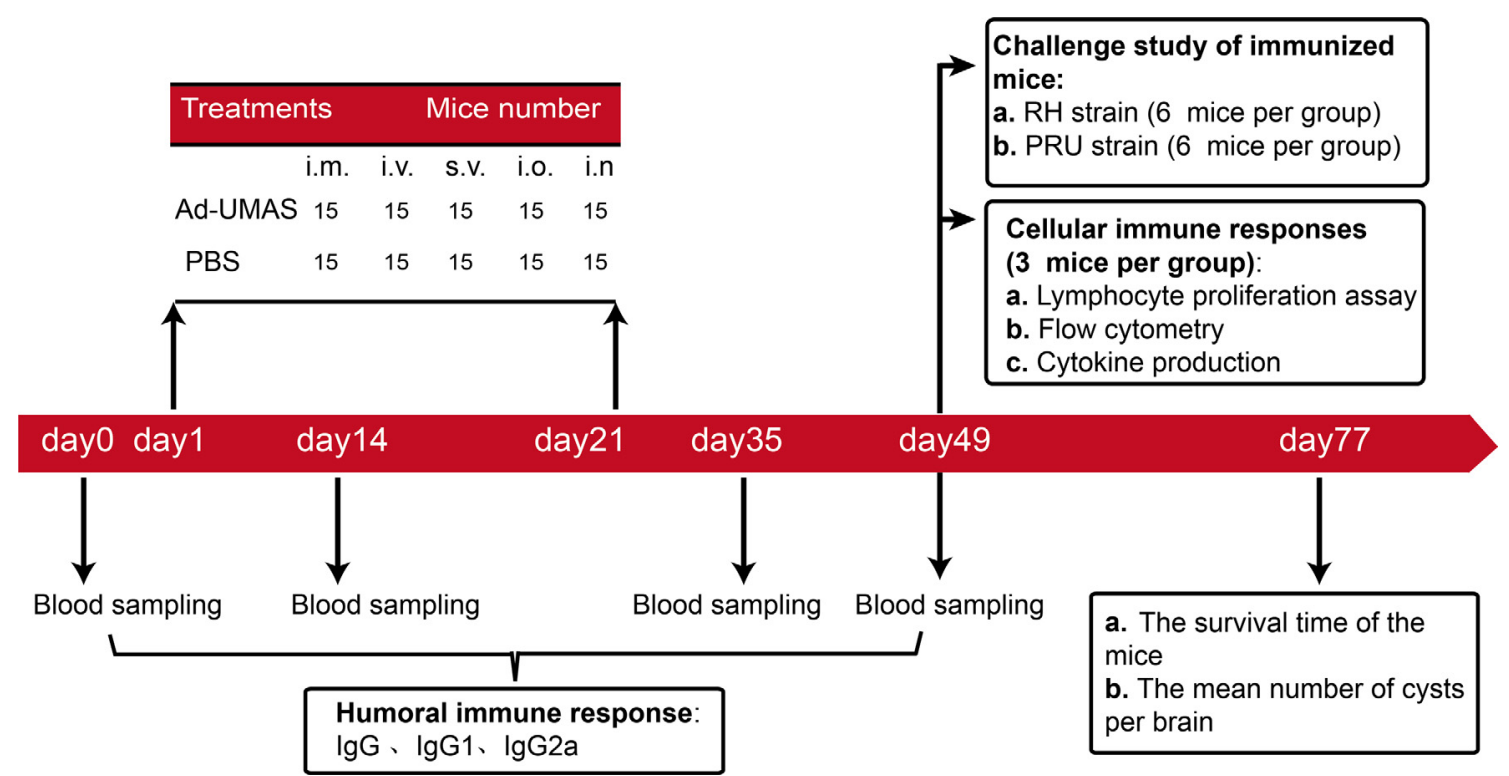

Figure 1. Study flowchart presenting groups of mice vaccinated with Ad-UMAS via different immunization routes.

later and the brains were removed and homogenized in $1 \mathrm{~mL}$ PBS. The mean number of cysts per brain was determined by counting three samples of $10 \mu \mathrm{L}$ aliquots from each homogenized brain under an optical microscope [20].

\section{Statistical analysis}

Statistical significances between the groups were calculated by one-way analysis of variance (ANOVA) using SPSS 19.0 software. The survival rate was compared by the Kaplan-Meier method. A $p$-value of less than $0.05(p<0.05)$ was considered to be significant.

\section{Results}

\section{Humoral IgG antibody was induced via all immunization routes}

To assess the systemic humoral immune responses obtained with the five immunization routes of Ad-UMAS, we collected sera at different times after the immunization, and anti- $T$. gondii $\operatorname{IgG}$ and $\operatorname{IgG}$ subtypes were detected by ELISA. As shown in Figure 2A, the levels of antibody titers all increased in the five Ad-UMAS immunization routes. Compared to the control, levels of $T$. gondii-specific IgG antibodies increased dramatically in the sera of all vaccination mice from day 14 to day 35 and achieved the highest on day 49 $(p<0.05)$. Among different immunization routes, the intramuscular group achieved the highest titer of IgG antibodies, then the subcutaneous, nasal, and oral groups, in decreasing order (Fig. 2B). In the intravenous vaccination group, the titer of IgG increased rapidly at 2 weeks and gradually more slowly thereafter, making the final titer relatively low.

Further evaluation of serum IgG subtype antibody revealed that $T$. gondii-specific $\operatorname{IgG} 1$ and $\operatorname{IgG} 2 \mathrm{a}$ antibody levels were both significantly increased in five Ad-UMAS vaccination groups as compared with the control $(p<0.05)$, while their differences were substantial in $\operatorname{IgG} 2$ a but not in $\operatorname{IgG1}$. The values of IgG2a antibody were relatively higher in the intramuscular and subcutaneous vaccination groups than with other vaccination routes (Figs. 2C and 2D).

\section{Higher mucosal immune responses were induced by intraoral and intranasal vaccination of Ad-UMAS}

To evaluate the ability of Ad-UMAS to induce local mucosal immune responses via the five pathways, mucosal IgA antibody response was detected in the collected mouse sera.

As shown in Figure 2E, vaccination in the intraoral and intranasal groups elicited strong $T$. gondii-specific IgA antibody levels that were significantly higher than other vaccination routes $(p<0.05)$ (Fig. $2 \mathrm{E})$. However, there were no statistically significant differences of IgA titer in the intramuscular, intravenous, and subcutaneous vaccination groups compared to control groups $(p>0.05)$.

\section{Robust cellular immune responses were induced via intranasal vaccination}

Cellular immune responses were first evaluated by analysis of the T-cell subset. The $\mathrm{CD} 4^{+}$and $\mathrm{CD} 8^{+} \mathrm{T}$ lymphocyte subsets in immunized mice were assayed by flow cytometry. Table 2 shows the percentage of $\mathrm{CD}^{+}$and $\mathrm{CD} 8^{+} \mathrm{T}$-cells, in comparison with control groups; the percentage of $\mathrm{CD}^{+} \mathrm{T}$-cells in all vaccination groups with Ad-UMAS increased significantly $(p<0.05)$. The percentages of $\mathrm{CD}^{+} \mathrm{T}$-cells in mice immunized intranasally $(36.5 \pm 1.8 \%)$, intraorally $(29.7 \pm 0.2 \%)$, and intramuscularly $(27.6 \pm 1.3 \%)$ were higher than in mice immunized by the subcutaneous and intranasal routes $(p<0.05)$. 
(A)

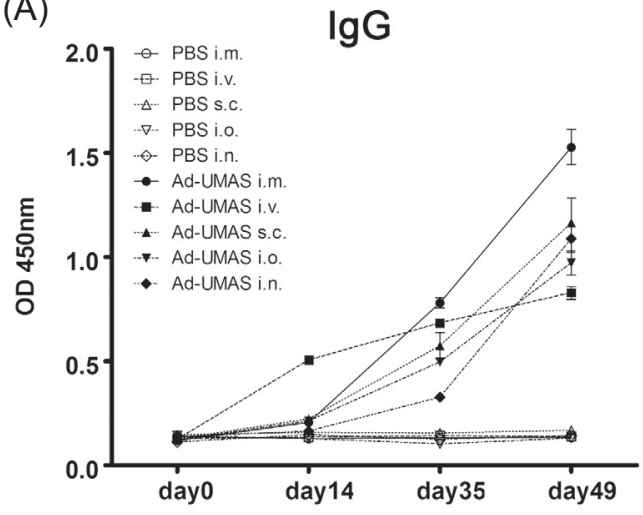

(C)

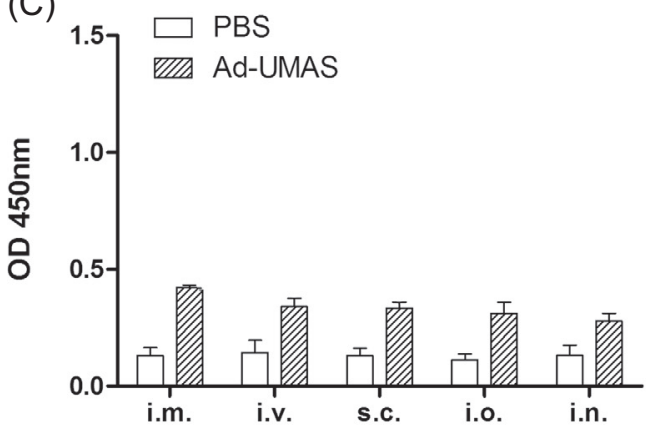

(E)

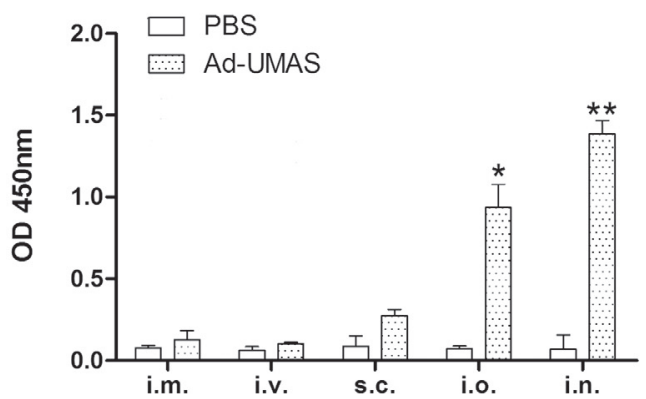

(B)

IgG titer
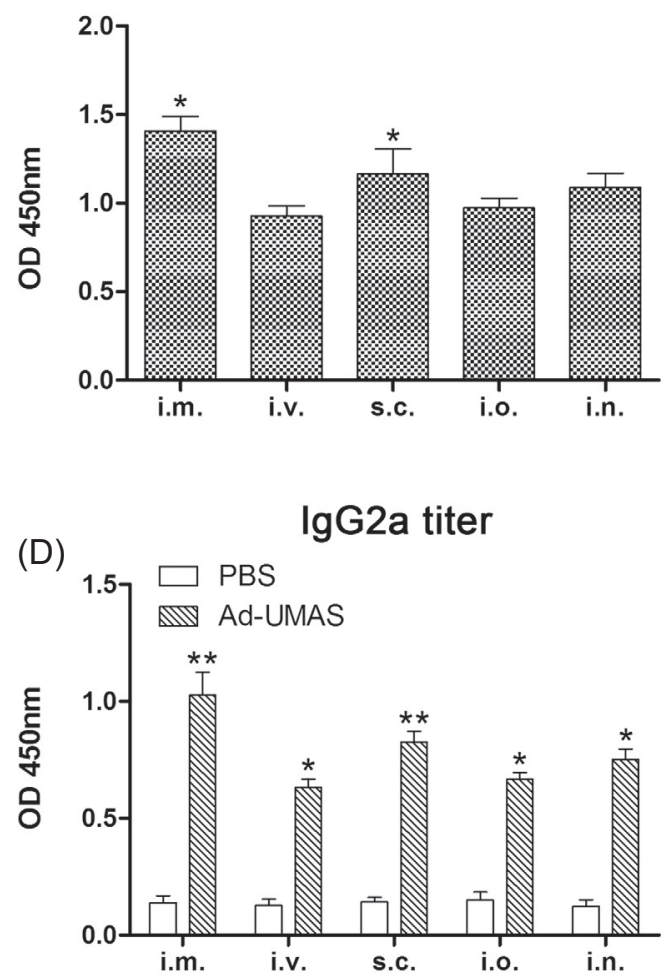

Figure 2. Systemic humoral immune response and local mucosal immune response induced by Ad-UMAS via different immunization routes. (A) IgG antibodies detected in murine serum collected on days $0,14,35$, and 49. (B) $\operatorname{IgG}$, (C) $\operatorname{IgG} 1$, (D) $\operatorname{IgG} 2 \mathrm{a}$, and (E) IgA titers were detected using sera from 4 weeks after the last vaccination. The results are expressed as the mean of the OD450 $\pm S D$ and are representative of three experiments. Asterisks mark the significant difference: ${ }^{*} p<0.05 ;{ }^{*} p<0.01$. Each bar represents the mean OD $( \pm S D, n=15)$.

The cell-mediated immunity induced in the immunized mice was further evaluated by measuring the amount of cytokines IL-2, IL-10, and IFN- $\gamma$. Table 3 shows the values of IL-2, IFN- $\gamma$, and IL-10 in all vaccination groups. The highest levels of IL-2 and IFN- $\gamma$ were detected in the nasal immunization group at $638.7 \pm 17.6 \mathrm{pg} / \mathrm{mL}$ and $1429.8 \pm 37.6 \mathrm{pg} / \mathrm{mL}$, respectively. Furthermore, the lymphocyte proliferation ability was also higher in the mice inoculated nasally with Ad-UMAS than the controls $(p<0.05)$. However, there were no statistically significant differences in the amount of IL-10 between all the immunization group and control groups $(p>0.05)$ (Table 3).

\section{Protective efficacy against the type I and type II parasites}

To evaluate the protective immunity, six mice of each group were given an intraperitoneal injection of $1 \times 10^{3}$ tachyzoites of $T$. gondii $\mathrm{RH}$ strain at 4 weeks after vaccination. The survival rates of mice immunized via different routes are shown in Figure 3. The mice immunized with Ad-UMAS via i.m., i.o., and i.n. showed an almost $50 \%$ survival rate and lower survival rates of $40 \%$ were found in the i.v. and s.c. immunization groups 28 days after challenge. All the control mice died within 8 days. 
Table 2. $\mathrm{CD}^{+}$and $\mathrm{CD}^{+}$subtypes of T-cells from immunized mice measured using flow cytometry.

\begin{tabular}{|c|c|c|c|c|}
\hline \multirow[t]{2}{*}{ Immunization routes $^{\mathrm{a}}$} & \multirow[t]{2}{*}{ Immunization regimen } & \multicolumn{2}{|c|}{$\begin{array}{l}\text { Percentage of positive stained cells } \\
(\% \text { : mean } \pm S D n=3)^{\mathrm{b}}\end{array}$} & \multirow[t]{2}{*}{$\mathrm{CD}^{+} / \mathrm{CD} 8^{+}$} \\
\hline & & $\mathrm{CD}^{+}$ & $\mathrm{CD}^{+}$ & \\
\hline \multirow[t]{2}{*}{ Intramuscular } & PBS & $21.6 \pm 0.9$ & $10.7 \pm 0.6$ & 2.02 \\
\hline & Ad-UMAS & $35.7 \pm 0.8$ & $27.6 \pm 1.3$ & 1.29 \\
\hline \multirow[t]{2}{*}{ Intravenous } & PBS & $20.3 \pm 1.2$ & $9.6 \pm 0.4$ & 2.11 \\
\hline & Ad-UMAS & $25.6 \pm 1.0$ & $18.9 \pm 1.4$ & 1.35 \\
\hline \multirow[t]{2}{*}{ Subcutaneous } & PBS & $19.1 \pm 0.7$ & $9.3 \pm 0.6$ & 2.05 \\
\hline & Ad-UMAS & $28.5 \pm 0.4$ & $22.6 \pm 1.2$ & 1.26 \\
\hline \multirow[t]{2}{*}{ Intraoral } & PBS & $21.4 \pm 0.5$ & $11.2 \pm 0.8$ & 1.91 \\
\hline & Ad-UMAS & $37.4 \pm 0.7^{*}$ & $29.7 \pm 0.2 *$ & $1.26^{*}$ \\
\hline \multirow[t]{2}{*}{ Intranasal } & PBS & $20.9 \pm 1.3$ & $10.1 \pm 0.8$ & 2.07 \\
\hline & Ad-UMAS & $40.6 \pm 1.1^{* *}$ & $36.5 \pm 1.8^{* *}$ & $1.11^{* *}$ \\
\hline
\end{tabular}

${ }^{a}$ Mice were immunized by five immunization routes, intramuscular, intravenous, subcutaneous, intraoral, or intranasal, on day 0 and day 21 with different immunization regimens.

${ }^{\mathrm{b}}$ The splenocyte culture supernatants taken from mice ( $n=3$, each group) 2 weeks after the last immunization were stained with FITClabeled anti-mouse $\mathrm{CD} 8^{+}$monoclonal antibody and PE-labeled anti-mouse $\mathrm{CD} 4^{+}$monoclonal antibody; $\mathrm{T}$ lymphocyte subsets were measured using flow cytometry. Asterisks mark the significant difference:

${ }^{*} p<0.05$;

$p<0.01$

Each bar represents the mean OD $( \pm S D)$.

Table 3. Cytokine production and cell proliferative assay in the splenocyte cultures obtained from immunized mice.

\begin{tabular}{llcccc}
\hline Immunization routes $^{\mathrm{a}}$ & Immunization regimen & \multicolumn{2}{c}{${\text { Cytokine production }(\mathrm{pg} / \mathrm{mL})^{\mathrm{b}}}^{\text {Stimulation index }^{\mathrm{c}}}$} \\
\cline { 3 - 5 } & & \multicolumn{1}{c}{ IL-2 } & \multicolumn{1}{c}{ IL-10 } & IFN- $\gamma$ \\
\hline Intramuscular & PBS & $78 \pm 8.5$ & $51 \pm 9.7$ & $103 \pm 9.7$ & 0.37 \\
& Ad-UMAS & $454.2 \pm 15.1$ & $48.7 \pm 5.1$ & $1085.6 \pm 25.1$ & 1.52 \\
Intravenous & PBS & $56 \pm 9.3$ & $43 \pm 8.1$ & $92 \pm 6.4$ & 0.25 \\
& Ad-UMAS & $320.5 \pm 9.6$ & $55.5 \pm 3.6$ & $920.1 \pm 19.6$ & 0.94 \\
Subcutaneous & PBS & $86 \pm 10.4$ & $64 \pm 4.6$ & $83 \pm 12.7$ & 0.31 \\
& Ad-UMAS & $425.4 \pm 13.7$ & $54.3 \pm 6.7$ & $989.1 \pm 43.7$ & 1.04 \\
Intraoral & PBS & $74 \pm 7.8$ & $57 \pm 8.3$ & $86 \pm 7.8$ & 0.62 \\
& Ad-UMAS & $527.2 \pm 8.1^{*}$ & $58.2 \pm 5.1$ & $1204.2 \pm 28.1^{*}$ & $2.13^{*}$ \\
Intranasal & PBS & $63 \pm 11.7$ & $62 \pm 6.7$ & $98 \pm 10.5$ & 0.58 \\
& Ad-UMAS & $638.7 \pm 17.6^{* *}$ & $42.1 \pm 2.6$ & $1429.8 \pm 37.6^{* *}$ & $2.93^{* *}$ \\
\hline
\end{tabular}

${ }^{a}$ Mice were immunized by five immunization routes: intramuscular, intravenous, subcutaneous, intraoral, and intranasal on day 0 and day 21 with different immunization regimens.

${ }^{\mathrm{b}}$ The splenocyte culture supernatants taken from mice ( $n=3$, each group) 2 weeks after the last immunization were examined for cytokine production by ELISA obtained at $24 \mathrm{~h}$ for IL-2, at $72 \mathrm{~h}$ for IL-10, and $96 \mathrm{~h}$ for IFN- $\gamma$.

${ }^{c}$ The results of proliferation assays are expressed as the stimulation index, calculated as the ratio between the mean counts per minute (cpm) for triplicate stimulated cultures and the mean counts per min for triplicate unstimulated cultures. Asterisks mark the significant difference: ${ }_{* *}^{*} p<0.05$ ${ }^{* *} p<0.01$.

Each bar represents the mean OD $( \pm S D)$.

The level of protective effect against chronic infection was evaluated by counting cysts in the brains of mice challenged with 20 cysts of the PRU strain of T. gondii (Fig. 3). An obvious reduction in the burden of brain cyst was detected in all the immunized mice compared with the control mice $(p<0.05)$. The brain cyst numbers in the oral and nasal immunization groups were significantly reduced to $459 \pm 34$ and $398 \pm 61$, respectively, which is much lower than the other immunization groups with injection in muscle $(569 \pm 23)$, via the venous route $(892 \pm 51)$, and via the subcutaneous route $(675 \pm 65)$ $(p<0.05)$.

\section{Discussion}

The antigen delivery pathway is a key parameter for the induction of protective immune responses by vaccines against intracellular pathogens [10]. As a novel inoculation, 
(A)

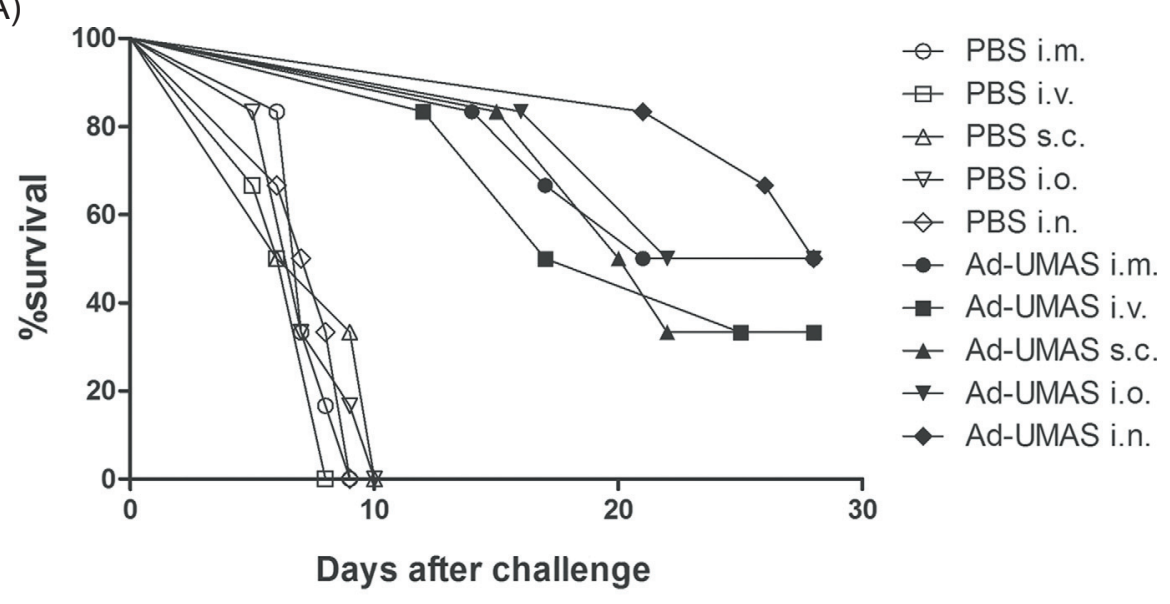

(B)

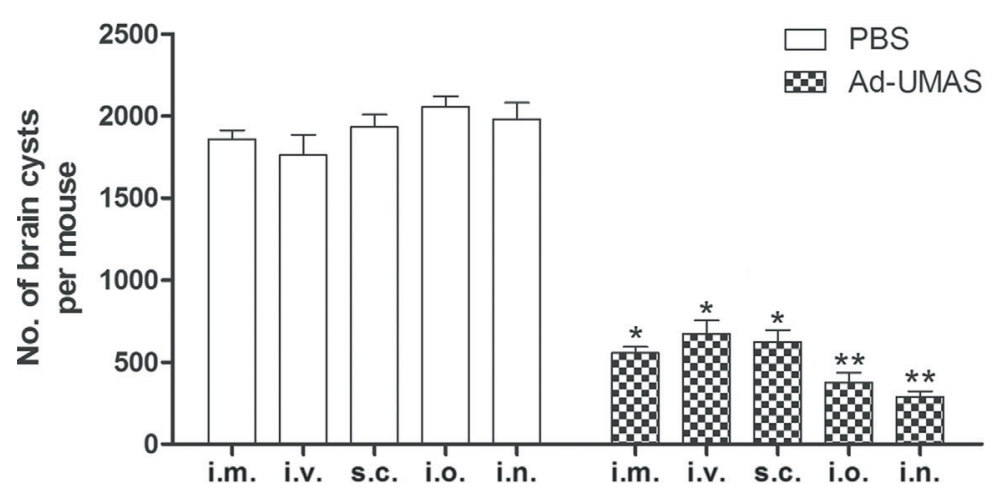

Figure 3. Evaluation of the protective ability against T. gondii infection. (A) Six immunized mice per group were infected intraperitoneally with $1 \times 10^{3}$ tachyzoites of T. gondii RH strain 4 weeks after the last immunization. Survival was monitored daily for 28 days after challenge. (B) Another six immunized mice per group were infected intragastrically with 20 cysts of T. gondii PRU strain and the cyst burden in the brain of vaccinated mice was counted 4 weeks later. The mean number of cysts in every mouse group was based on each mouse brain cyst in the group. Asterisks mark the significant difference: ${ }^{*} p<0.05 ;{ }^{* *} p<0.05$. Each bar represents the mean OD $( \pm S D)$.

there is general agreement that effective mucosal vaccines (oral, nasal, sublingual, and genital tract vaccines) could dramatically stimulate protective immune responses not only against mucosal infections but also against HIV, Mycobacterium tuberculosis, and many other pathogens $[8,37]$. In this study, we compared the capability of Ad-UMAS to induce systemic humoral and cellular immune responses, and local mucosal immune responses via five vaccination pathways (i.m., i.v., s.c., i.o., and i.n.).

Mucosal vaccines are advantageous compared with systemic vaccines from a production and regulatory perspective $[18,23]$. Previous studies have revealed that a Middle East respiratory syndrome (MERS) vaccine greatly enhances local mucosal immune responses in immunized BALB/c mice with the intranasal inoculation method [24]. Ideal attenuated vaccines could be engineered to have a limited capacity for replication and to deliver an effective antigen, while avoiding unwanted inflammatory responses [35, 39, 41]. Recombinant adenoviruses are some of the most intensively investigated vaccine carriers in many pathogenic infections, such as Ebola virus, HIV, and the malaria parasite $[1,11,16,32]$. Several clinical trials have shown that vaccines based on adenoviruses could elicit vigorous and sustained T-cell responses, with the advantage of safety and high immunogenicity [25].

Our results showed that the Ad-UMAS vaccine could effectively improve the humoral response intramuscular pathway. Systemic humoral IgG antibody responses induced by the intraoral and intranasal vaccination pathway were comparable to those induced by the other pathway in the collected mouse sera. Interestingly, we found that IgG antibody in the intravenous vaccination group increased very sharply at first but slowly later on, even after the boost immunization. It should be considered that antigens that are transmitted to the bloodstream directly can induce strong immune responses in the early stage, but can also cause immune tolerance, explaining why antibody levels increase slowly in the following time [25].

Moreover, evaluation of serum $\operatorname{IgG}$ subtype antibody responses revealed that all vaccination pathways induced a relatively higher level of Th1-associated IgG2a than Th2associated IgG1 in this study. It should be noted that Ad-UMAS induced a slightly biased Th1-associated antibody 
response. It is known that production of IgG subtype is driven by cytokines secreted during cellular immune responses. Therefore, the presence of IgG1 and IgG2a indirectly suggests that the vaccination protocol also promoted activation of a cellmediated response $[12,31]$. These data suggest that Ad-UMAS immunization by the mucosal vaccination route was capable of eliciting similar systemic humoral antibody responses compared with those elicited by the intramuscular pathway in vaccinated mice.

Mucosal vaccines against Toxoplasma infection require the induction of protective responses at mucosal surfaces and also the induction of systemic protective immune responses in the systemic compartment [18]. As the first line of defense in protecting mucous membranes, specific SIgA plays a protective role against many pathogens. Therefore, vaccines capable of inducing strong local mucosal immunity represented by secretory IgA would be helpful in preventing $T$. gondii infection [9]. Our data indicated that $T$. gondii-specific $\operatorname{IgA}$ antibody responses in vaccinated mouse sera were elicited by i.n. and i.o vaccination of Ad-UMAS, which were significantly higher than those induced by other vaccination routes, confirming the ability of Ad-UMAS to induce strong mucosal immunity via the mucosal route.

The memory T-cell consists of $\mathrm{CD}^{+}$and $\mathrm{CD}^{+}$T-cells, which play a vital role in the establishment of protective immunity in hosts [31]. $\mathrm{CD}^{+} \mathrm{T}$-cells can control the spreading and development of $T$. gondii infection in synergy with $\mathrm{CD}^{+}$ T-cells [12]. In our study, $\mathrm{CD}^{+}$and $\mathrm{CD}^{+} \mathrm{T}$ lymphocyte subsets from immunized mice were assayed by flow cytometry. There was a marked increase in the percentage of $\mathrm{CD} 8^{+} \mathrm{T}$-cells in mice immunized with the Ad-UMAS vaccine via mucosal routes. Cytokines play a critical role in the activities of Th cells. As we know, Th1 cells are responsible for limiting tissue extension of the parasite through the production of IL-2 and IFN- $\gamma$ [15]. Our results show that in contrast with the blank control, high levels of IL-2 and IFN- $\gamma$ were induced in mice immunization with Ad-UMAS especially treated intraorally and intranasally. However, there is no difference in IL-10 production between vaccinated and control groups. Additionally, splenocyte proliferation activity was significantly enhanced in mice immunized via oral and nasal routes. These results clearly suggest that mucosal vaccination with Ad-UMAS can significantly augment Th1-mediated cellular immune responses in which $\mathrm{CD}^{+} \mathrm{T}$ lymphocytes are considered as major effectors responsible for controlling parasite infection and secreting IFN- $\gamma$ during the cellular response against toxoplasmosis.

In our study, a highly virulent RH strain and a mild virulent PRU strain of $T$. gondii were used for the challenge study. With the RH strain, it is easy to induce acute infection in mice through intraperitoneal injection with tachyzoites. The PRU strain is more likely to induce chronic infection in mice following intragastric administration with cysts [36]. In order to simulate acute and chronic infection in the host, mice were infected with the RH strain and PRU strain by different challenge routes. When challenged with lethal doses of T. gondii $\left(1 \times 10^{3}\right)$, all five groups immunized with Ad-UMAS had a prolonged survival time as compared with control mice. In particular, mice immunized intranasally and intraorally showed higher survival rates than with the other immunization routes. Since protection via vaccination was not $100 \%$ because the strain of the parasite has high mortality and the dose of $\mathrm{RH}$ parasites for immunized mice was larger, the optimal challenge dose should be determined in the future. Furthermore, the higher mucosal immune responses that were induced by intraoral and intranasal vaccination of Ad-UMAS may explain the significant reduction in the cyst burden in the mice immunized with Ad-UMAS intraorally and intranasally, which exhibited reductions of $75.3 \%$ and $78.6 \%$ of brain cysts, respectively.

Earlier studies [14, 26, 34] have determined mortality, cytokine production, and parasite burden after challenge infection in susceptible and resistant strains of mice with the same or similar doses of $T$. gondii parasites. These studies found that different inbred strains of mice have markedly different susceptibility to $T$. gondii infection. These susceptibility differences may be due to differences in the virulence of the parasite itself or differences in the genetic make-up of the mice in terms of their immune response. In our study, only one inbred strain of mice was used for the experiment. It is therefore necessary to assess the different immunizations in different strains of mice in future research.

In summary, mucosal immunization with recombinant adenovirus vaccine expressing ubiquitin-conjugated multistage antigen segments (Ad-UMAS) is a potential vaccination route to elicit protective immune responses. Compared to other immunization routes, oral and nasal immunizations with Ad-UMAS elicit both robust systemic and mucosal immune responses, accompanied by a significant increase in survival rates after challenge with highly virulent parasites and a dramatic reduction in brain cyst burdens in vaccinated mice after challenge with mild strains of $T$. gondii. Therefore, the results of this study should contribute to the development of an effective and safe mucosal vaccine for preventing $T$. gondii infection.

\section{Conflict of interest}

The authors declare that they have no competing interests.

Acknowledgements. This study was supported by grants from the National Natural Science Foundation Project of China (Grant No. $81171604)$ and the Development Project of Shandong Province (Grant No. 2016GSF201201).

\section{References}

1. Choi JH, Jonsson-Schmunk K, Qiu X, Shedlock DJ, Strong J, Xu JX, Michie KL, Audet J, Fernando L, Myers MJ, Weiner D, Bajrovic I, Tran LQ, Wong G, Bello A, Kobinger GP, Schafer SC, Croyle MA. 2015. A single dose respiratory recombinant adenovirus-based vaccine provides long-term protection for non-human primates from lethal Ebola infection. Molecular Pharmacology, 12(8), 2712-2731.

2. Cong H, Mui EJ, Witola WH, Sidney J, Alexander J, Sette A, Maewal A, EI Bissati K, Zhou Y, Suzuki Y, Lee D, Woods S, Sommerville C, Henriquez FL, Roberts CW, McLeod R. 2012. 
Toxoplasma gondii HLA-B*0702-restricted GRA7(20-28) peptide with adjuvants and a universal helper $\mathrm{T}$ cell epitope elicits CD8(+) T cells producing interferon-gamma and reduces parasite burden in HLA-B*0702 mice. Human Immunology, 73(1) $1-10$.

3. Cong H, Mui EJ, Witola WH, Sidney J, Alexander J, Sette A, Maewal A, McLeod R. 2010. Human immunome, bioinformatic analyses using HLA supermotifs and the parasite genome, binding assays, studies of human $\mathrm{T}$ cell responses, and immunization of HLA-A*1101 transgenic mice including novel adjuvants provide a foundation for HLA-A03 restricted $\mathrm{CD}^{+} \mathrm{T}$ cell epitope based, adjuvanted vaccine protective against Toxoplasma gondii. Immunome Research, 6, 12.

4. Cong H, Mui EJ, Witola WH, Sidney J, Alexander J, Sette A, Maewal A, McLeod R. 2011. Towards an immunosense vaccine to prevent toxoplasmosis: protective Toxoplasma gondii epitopes restricted by HLA-A*0201. Vaccine, 29(4), 754-762.

5. Cong H, Yuan Q, Zhao Q, Zhao L, Yin H, Zhou H, He S, Wang Z. 2014. Comparative efficacy of a multi-epitope DNA vaccine via intranasal, peroral, and intramuscular delivery against lethal Toxoplasma gondii infection in mice. Parasites \& Vectors, 7, 145.

6. Dardé ML, Bouteille B, Pestre-Alexandre M. 1992. Isoenzyme analysis of 35 Toxoplasma gondii isolates and the biological and epidemiological implications. Journal of Parasitology, 78(5), 786-794.

7. Derouin F, Pelloux H. 2008. Prevention of toxoplasmosis in transplant patients. Clinical Microbiology and Infection, 14(12), 1089-1101.

8. Edele F, Dudda JC, Bachtanian E, Jakob T, Pircher H, Martin SF. 2014. Efficiency of dendritic cell vaccination against B16 melanoma depends on the immunization route. PLoS One, 9(8), e105266.

9. Fiorino F, Pettini E, Pozzi G, Medaglini D, Ciabattini A. 2013. Prime-boost strategies in mucosal immunization affect local IgA production and the type of th response. Frontiers in Immunology, 4, 128.

10. Fynan EF, Webster RG, Fuller DH, Haynes JR, Santoro JC, Robinson HL. 1993. DNA vaccines: protective immunizations by parenteral, mucosal, and gene-gun inoculations. Proceedings of the National Academy of Sciences of the United States of America, 90(24), 11478-11482.

11. Gray GE, Moodie Z, Metch B, Gilbert PB, Bekker LG, Churchyard G, Nchabeleng M, Mlisana K, Laher F, Roux S, Mngadi K, Innes C, Mathebula M, Allen M, McElrath MJ, Robertson M, Kublin J, Corey L, HVTN 503/Phambili study team. 2014. Recombinant adenovirus type $5 \mathrm{HIV}$ gag/pol/nef vaccine in South Africa: unblinded, long-term follow-up of the phase 2b HVTN 503/Phambili study. Lancet Infectious Diseases, 14(5), 388-396.

12. Henriquez FL, Woods S, Cong H, McLeod R, Roberts CW. 2010. Immunogenetics of Toxoplasma gondii informs vaccine design. Trends in Parasitology, 26(11), 550-555.

13. Innes EA. 2010. A brief history and overview of Toxoplasma gondii. Zoonoses and Public Health, 57(1), 1-7.

14. Johnson J, Suzuki Y, Mack D, Mui E, Estes R, David C, Skamene E, Forman J, McLeod R. 2002. Genetic analysis of influences on survival following Toxoplasma gondii infection. International Journal for Parasitology, 32, 179-185.

15. Jongert E, Lemiere A, Van Ginderachter J, De Craeye S, Huygen K, D'Souza S. 2010. Functional characterization of in vivo effector $\mathrm{CD} 4(+)$ and $\mathrm{CD} 8(+) \mathrm{T}$ cell responses in acute toxoplasmosis: an interplay of IFN-gamma and cytolytic T cells. Vaccine, 28(13), 2556-2564.

16. Karen KA, Deal C, Adams RJ, Nielsen C, Ward C, Espinosa DA, Xie J, Zavala F, Ketner G. 2015. A replicating adenovirus capsid display recombinant elicits antibodies against Plasmodium falciparum sporozoites in Aotus nancymaae monkeys. Infection and Immunity, 83(1), 268-275.

17. Kijlstra A, Petersen E. 2014. Epidemiology, pathophysiology, and the future of ocular toxoplasmosis. Ocular Immunology and Inflammation, 22(2), 138-147.

18. Kweon MN. 2014. Recent progress in mucosal immunology and vaccine development. Experimental \& Molecular Medicine, 46, e86.

19. Lim SS, Othman RY. 2014. Recent advances in Toxoplasma gondii immunotherapeutics. Korean Journal of Parasitology, 52, $581-593$

20. Liu Q, Wang F, Wang G, Zhao Q, Min J, Wang S, Cong H, Li Y, He S, Zhou H. 2014. Toxoplasma gondii: immune response and protective efficacy induced by ROP16/GRA7 multicomponent DNA vaccine with a genetic adjuvant B7-2. Human Vaccines \& Immunotherapeutics, 10(1), 184-191.

21. Li XZ, Lv L, Zhang X, Anchang KY, Abdullahi AY, Tu L, Wang X, Xia L, Zhang XX, Feng W, Lu C, Li S, Yuan ZG. 2016. Recombinant canine adenovirus type-2 expressing TgROP16 provides partial protection against acute Toxoplasma gondii infection in mice. Infection Genetics and Evolution, 45, 447-453.

22. Li XZ, Wang XH, Xia LJ, Weng YB, Hernandez JA, Tu LQ, Li LT, Li SJ, Yuan ZG. 2015. Protective efficacy of recombinant canine adenovirus type- 2 expressing TgROP18 (CAV-2ROP18) against acute and chronic Toxoplasma gondii infection in mice. BMC Infectious Diseases, 15, 114.

23. Lycke N. 2012. Recent progress in mucosal vaccine development: potential and limitations. Nature reviews. Immunology, 12(8), 592-605.

24. Ma C, Li Y, Wang L, Zhao G, Tao X, Tseng CT, Zhou Y, Du L, Jiang S. 2014. Intranasal vaccination with recombinant receptor-binding domain of MERS-CoV spike protein induces much stronger local mucosal immune responses than subcutaneous immunization: Implication for designing novel mucosal MERS vaccines. Vaccine, 32(18), 2100-2108.

25. Malvey EN, Jenkins MK, Mueller DL. 1998. Peripheral immune tolerance blocks clonal expansion but fails to prevent the differentiation of Th1 cells. Journal of Immunology, 161(5), 2168-2177.

26. McLeod R, Eisenhauer P, Mack D, Brown C, Filice G, Spitalny G. 1989. Immune responses associated with early survival after peroral infection with Toxoplasma gondii. Journal of Immunology, 142, 3247-3255.

27. Mendes EA, Caetano BC, Penido ML, Bruna-Romero O, Gazzinelli RT. 2011. MyD88-dependent protective immunity elicited by adenovirus 5 expressing the surface antigen 1 from Toxoplasma gondii is mediated by CD8 (+) T lymphocytes. Vaccine, 29(27), 4476-4484.

28. Meng M, He S, Zhao G, Bai Y, Zhou H, Cong H, Lu G, Zhao Q, Zhu XQ. 2012. Evaluation of protective immune responses induced by DNA vaccines encoding Toxoplasma gondii surface antigen 1 (SAG1) and 14-3-3 protein in BALB/c mice. Parasites \& Vectors, 5, 273.

29. Montoya JG, Liesenfeld O. 2004. Toxoplasmosis. Lancet, 363(9425), 1965-1976. 
30. Paquet C, Yudin MH. 2013. Toxoplasmosis in pregnancy: prevention, screening, and treatment. Journal of Obstetrics and Gynaecology Canada, 35(1), 78-81.

31. Pifer R, Yarovinsky F. 2011. Innate responses to Toxoplasma gondii in mice and humans. Trends in Parasitology, 27(9), 388-393.

32. Rosa DS, Ribeiro SP, Almeida RR, Mairena EC, Kalil J, Cunha-Neto E. 2011. A recombinant adenovirus encoding multiple HIV-1 epitopes induces stronger CD4 T cell responses than a DNA vaccine in mice. Vaccines and Vaccination, 2(4), $1-17$.

33. Sabin AB. 1941. Toxoplasmic encephalitis in children. Journal of the American Medical Association, 116, 801-807.

34. Schlüter D, Deckert-Schluter M, Lorenz E, Meyer T, Rollinger M, Bogdan C. 1999. Inhibition of inducible nitric oxide synthase exacerbates chronic cerebral toxoplasmosis in Toxoplasma gondii-susceptible C57BL/6 mice but does not reactivate the latent disease in $T$. gondii-resistant $\mathrm{BALB} / \mathrm{c}$ mice. Journal of Immunology, 162, 3512-3518.

35. Singh S, Vedi S, Li W, Samrat SK, Kumar R, Agrawal B. 2014. Recombinant adenoviral vector expressing HCV NS4 induces protective immune responses in a mouse model of VacciniaHCV virus infection: a dose and route conundrum. Vaccine, 32(23), 2712-2721.

36. Sullivan WJ, Jeffers V. 2012. Mechanisms of Toxoplasma gondii persistence and latency. FEMS Microbiology Reviews, 36, 717-733.

37. Valdenegro-Vega VA, Crosbie P, Vincent B, Cain KD, Nowak BF. 2013. Effect of immunization route on mucosal and systemic immune response in Atlantic salmon (Salmo salar). Veterinary Immunology and Immunopathology, 151(1-2), 113-123.

38. Verma R, Khanna P. 2013. Development of Toxoplasma gondii vaccine: A global challenge. Human Vaccines \& Immunotherapeutics, 9(2), 291-293.

39. Xiang Z, Ertl HC. 1999. Induction of mucosal immunity with a replication-defective adenoviral recombinant. Vaccine, 17(15-16), 2003-2008.

40. Yin H, Zhao L, Wang T, Zhou H, He S, Cong H. 2015. A Toxoplasma gondii vaccine encoding multistage antigens in conjunction with ubiquitin confers protective immunity to $\mathrm{BALB} / \mathrm{c}$ mice against parasite infection. Parasites \& Vectors, 8 , 498.

41. Yu L, Yamagishi J, Zhang S, Jin C, Aboge GO, Zhang H, Zhang G, Tanaka T, Fujisaki K, Nishikawa Y, Xuan X. 2012. Protective effect of a prime-boost strategy with plasmid DNA followed by recombinant adenovirus expressing TgAMA1 as vaccines against Toxoplasma gondii infection in mice. Parasitology International, 61(3), 481-486.

42. Zhang M, Zhao L, Song J, Li Y, Zhao Q, He S, Cong H. 2013. DNA vaccine encoding the Toxoplasma gondii bradyzoitespecific surface antigens SAG2CDX protect $\mathrm{BALB} / \mathrm{c}$ mice against type II parasite infection. Vaccine, 31(41), 4536-4540.

43. Zhao L, Zhang M, Cong H. 2013. Advances in the study of HLA-restricted epitope vaccines. Human Vaccines \& Immunotherapeutics, 9(12), 2566-2577.

44. Zhou H, Min J, Zhao Q, Gu Q, Cong H, Li Y, He S. 2012. Protective immune response against Toxoplasma gondii elicited by a recombinant DNA vaccine with a novel genetic adjuvant. Vaccine, 30(10), 1800-1806.

Cite this article as: Wang T, Yin H, Li Y, Zhao L, Sun X \& Cong H: Vaccination with recombinant adenovirus expressing multi-stage antigens of Toxoplasma gondii by the mucosal route induces higher systemic cellular and local mucosal immune responses than with other vaccination routes. Parasite, 2017, 24, 12.

\section{PARASTE}

An international open-access, peer-reviewed, online journal publishing high quality papers on all aspects of human and animal parasitology

Reviews, articles and short notes may be submitted. Fields include, but are not limited to: general, medical and veterinary parasitology; morphology, including ultrastructure; parasite systematics, including entomology, acarology, helminthology and protistology, and molecular analyses; molecular biology and biochemistry; immunology of parasitic diseases; host-parasite relationships; ecology and life history of parasites; epidemiology; therapeutics; new diagnostic tools.

All papers in Parasite are published in English. Manuscripts should have a broad interest and must not have been published or submitted elsewhere. No limit is imposed on the length of manuscripts.

Parasite (open-access) continues Parasite (print and online editions, 1994-2012) and Annales de Parasitologie Humaine et Comparée (1923-1993) and is the official journal of the Société Française de Parasitologie. 